\title{
Mixing Time in a Bath Agitated Simultaneously by Bottom Gas Injection and Side Liquid Injection
}

\author{
Manabu Iguchi ${ }^{1}$, Yasushi Sasaki ${ }^{1}$, Nobuharu Kawabata ${ }^{2, *}$ and Toshikatsu Iwasaki ${ }^{2}$ \\ ${ }^{1}$ Division of Materials Science and Engineering, Graduate School of Engineering, Hokkaido University, Sapporo 060-8628, Japan \\ ${ }^{2}$ Department of Precision Engineering, Osaka Electro-Communication University, Neyagawa 572-0833, Japan
}

Effective mixing of a cylindrical bath is of crucial for wastewater treatment. Measurements were carried out on the mixing time in a cylindrical bath agitated simultaneously by bottom gas injection and side liquid injection. Air was injected into the bath through a centered single-hole bottom nozzle. Water was injected into the bath through a single-hole nozzle attached to the side wall of the vessel, drained from a pipe installed at the opposite bottom corner, and injected again with a small pump. The mixing time due to simultaneous gas and water injection, $T_{\mathrm{m} 3}$, was satisfactorily correlated by the following empirical equation.

$$
1 / T_{\mathrm{m} 3}=1 / T_{\mathrm{m} 1}+1 / T_{\mathrm{m} 2}
$$

where $T_{\mathrm{m} 1}$ and $T_{\mathrm{m} 2}$ are the mixing time values for water injection alone and gas injection alone, respectively. This relationship means that mixing by gas injection and that of liquid injection proceed in parallel with each other.

(Received February 16, 2004; Accepted May 14, 2004)

Keywords: wastewater treatment, gas injection, two-phase flow, liquid jet, mixing time

\section{Introduction}

Concerning the mixing time of batch-type metals refining processes agitated by gas injection, remarkable progress was achieved by pioneering work of Nakanishi et al. ${ }^{1)}$ Since then numerous investigations on the mixing time for various types of reactors agitated by gas injection have been carried out. ${ }^{2-9)}$

Gas injection techniques find wide applications in another fields of engineering. The present authors have applied the gas injection method to snow melting ${ }^{10)}$ and wastewater treatment. ${ }^{11)}$ The melting rate of snow and the efficiency of wastewater treatment were highly enhanced in the presence of the swirl motion. ${ }^{8,9)}$

In this study, particular attention was paid to the effect of liquid injection on the mixing time in a cylindrical water bath subjected to centered bottom gas injection. Water was injected into the bath through a circular nozzle installed flush-mount to the side wall of the vessel, drained through a pipe attached to the opposite bottom corner, and injected again to keep the bath surface constant. The water therefore was circulated. The mixing time was found to be independent of the tracer and sensor positions. An empirical equation was proposed for the mixing time in a bath agitated simultaneously by gas and water injection as a function of the mixing times for gas injection alone and water injection alone.

This agitation system can be applied to a batch type wastewater treatment. As mentioned above, the authors reported previously that refractory organic wastewater contained in a batch type vessel can be effectively processed by bottom gas injection. ${ }^{11)}$ The gas was a mixture of air and ozone. The efficiency of the treatment would be highly enhanced by simultaneous gas and liquid injection. This is the main reason why mixing time was chosen to quantitatively evaluate the intensity of mixing in the bath. If we use vessels of more than two, we can develop a continuous process for wastewater treatment. In this case, however, the residence time must be taken into consideration in place of mixing time.

\section{Experimental Apparatus and Procedure}

\subsection{Experimental apparatus}

Figures 1 and 2 show schematic diagrams of the experimental apparatus and test vessel, respectively. The mixing time was defined as a period for an instantaneous tracer concentration to settle within $\pm 5 \%$ deviation around the final constant tracer concentration in the bath (called 95\% criterion), as shown in Fig. 3.

Aqueous $\mathrm{KCl}$ solution with a concentration of $1 \mathrm{kmol} / \mathrm{m}^{3}$ was used as tracer. The volumetric concentration of the tracer

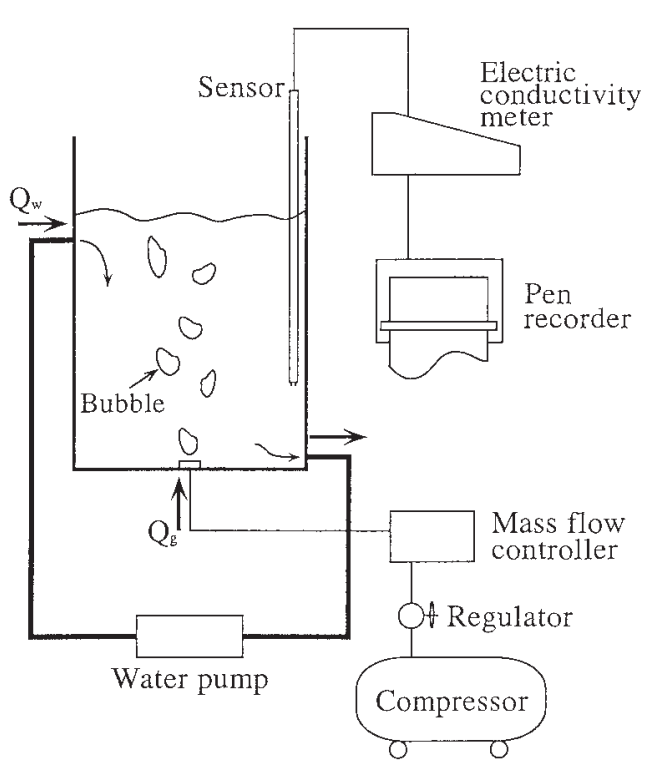

Fig. 1 Schematic diagram of experimental apparatus. 

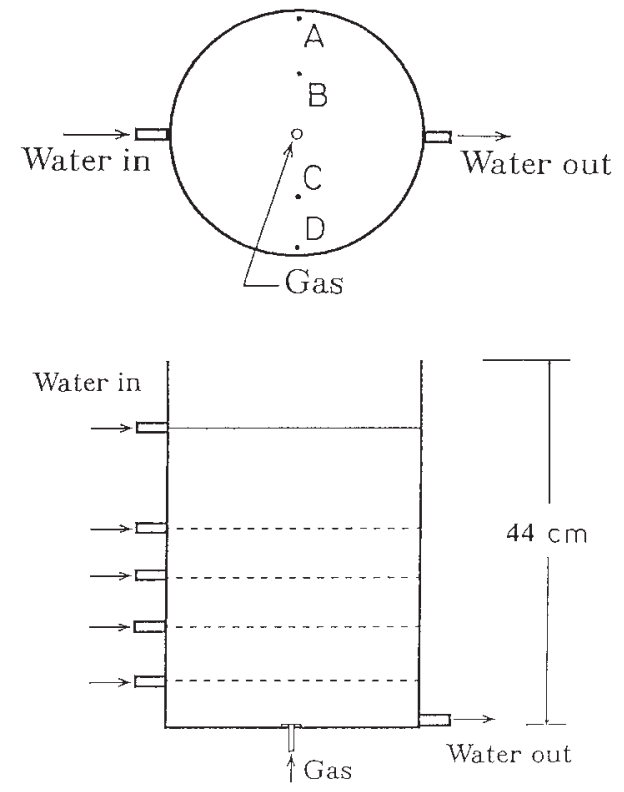

Fig. 2 Schematic of test vessel.

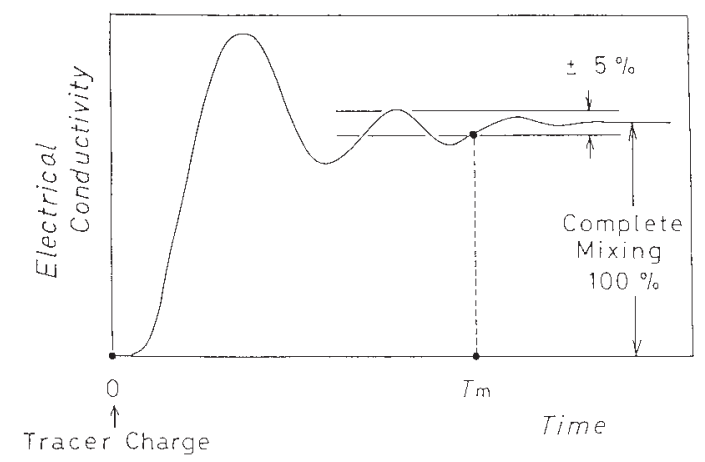

Fig. 3 Definition of mixing time.

in the bath was adjusted to be $0.1 \%$. The cylindrical vessel made of transparent acrylic resin had an inner diameter, $D$, of $20 \mathrm{~cm}$ and a height, $H$, of $44 \mathrm{~cm}$. Air was injected through a centered bottom nozzle with an inner diameter, $d_{\mathrm{n}}$, of $0.2 \mathrm{~cm}$. Water with the same temperature as the bath as well as the air was injected at a prescribed flow rate through a circular nozzle with an inner diameter, $d_{\mathrm{nw}}$, of $1.3 \mathrm{~cm}$. The nozzle exit was flush-mount to the side wall of the vessel. The height of the nozzle, $H_{\mathrm{ni}}$, for water injection was changed in the vertical direction. The water was drained through another pipe with the same inner diameter of $1.3 \mathrm{~cm}$, being located at the opposite bottom corner, and circulated by a small pump through a very short circulation pipe line.

The volume of water contained in the pump and circulation pipe line is less than $100 \mathrm{~cm}^{3}$, being very small compared with the volume of water of 1570 to $9400 \mathrm{~cm}^{3}$ in the cylindrical bath, and hence, almost all amount of tracer remains in the bath. Furthermore, the concentration of the tracer in the circulation pipe line is almost equal to that in the bath because the passing time of liquid through the line is much shorter than the measured mixing time. The mixing time value thus obtained, therefore, can be regarded as a good approximation of the real mixing time and would be useful to

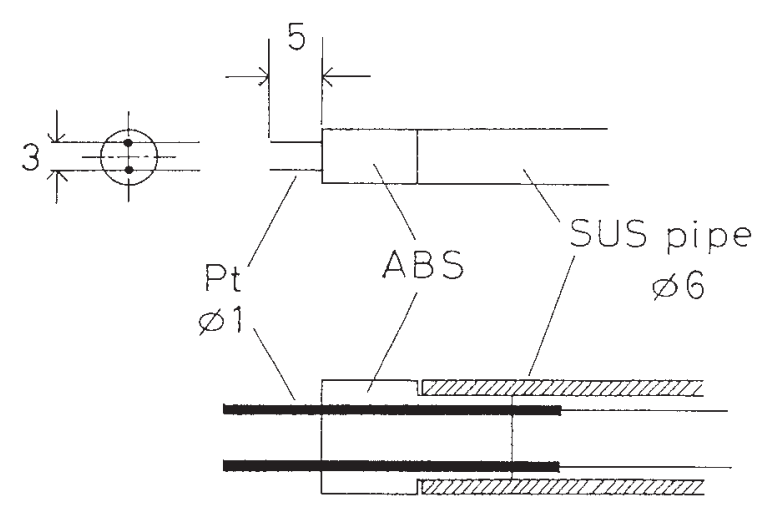

Fig. 4 Sensor of electric conductivity meter.

predict the mixing characteristics of practical reactors agitated by liquid injection.

The electrical conductivity of liquid in the bath was measured using a sensor shown in Fig. 4. The time constant of the present system composed of the electric conductivity meter and a pen recorder was $0.25 \mathrm{~s}$. The mixing time measurements were repeated ten times at each measurement position.

\subsection{Effects of sensor and tracer positions on mixing time}

Full understanding of the effects of sensor and tracer positions on the mixing time has not been obtained. ${ }^{2-9,12)} \mathrm{We}$ therefore investigated at first the effects of sensor and tracer positions on the mixing time.

\subsubsection{Vertical sensor position}

The radial sensor position was fixed at the position $\mathrm{A}$ $\left(r_{\mathrm{s}}=9 \mathrm{~cm}\right)$ in Fig. 2 and the sensor was placed at a vertical position of $H_{\mathrm{s}}=1,5,10,15,20$, or $25 \mathrm{~cm}$, where $H_{\mathrm{s}}$ was measured from the bottom of the bath. Tracer was added onto the bath surface at the radial position $\mathrm{D}$ of $r_{\mathrm{t}}=9 \mathrm{~cm}$, as shown in Fig. 2. The air and water flow rates, $Q_{\mathrm{g}}$ and $Q_{\mathrm{w}}$, were $120 \mathrm{~cm}^{3} / \mathrm{s}$ and $150 \mathrm{~cm}^{3} / \mathrm{s}$, respectively.

\subsubsection{Radial sensor and tracer positions}

The radial tracer position was fixed on the bath surface at the position $\mathrm{D}$ and the sensor was placed in turn at the position $\mathrm{A}, \mathrm{B}, \mathrm{C}$ or D. Later, the sensor was placed at the position $\mathrm{D}$ and the radial tracer position was shifted to the position $\mathrm{A}, \mathrm{B}$ or $\mathrm{C}$ to examine the symmetry of mixing time with respect to the line connecting the inlet and exit of the forced circulation pipe line. The other parameters were chosen as follows: $H_{\mathrm{s}}=1 \mathrm{~cm}, Q_{\mathrm{g}}=120 \mathrm{~cm}^{3} / \mathrm{s}$ and $Q_{\mathrm{w}}=150 \mathrm{~cm}^{3} / \mathrm{s}$.

\subsection{Effect of water flow rate, $Q_{\mathrm{w}}$, on mixing time}

The sensor was placed at $H_{\mathrm{s}}=1 \mathrm{~cm}$ and $r_{\mathrm{s}}=9 \mathrm{~cm}$ (Position A), and tracer was added onto the bath surface at the position $\mathrm{D}$. The water flow rate, $Q_{\mathrm{w}}$, was set at $0,50,100$, or $150 \mathrm{~cm}^{3} / \mathrm{s}$ for a gas flow rate of $Q_{\mathrm{g}}=120 \mathrm{~cm}^{3} / \mathrm{s}$.

\subsection{Effect of gas flow rate, $Q_{\mathrm{g}}$, on mixing time}

The sensor was placed at $H_{\mathrm{s}}=1 \mathrm{~cm}$ and $r_{\mathrm{s}}=9 \mathrm{~cm}$ (Position A), and the position D was chosen as the tracer position. The water flow rate was kept constant $\left(Q_{\mathrm{w}}=100 \mathrm{~cm}^{3} / \mathrm{s}\right)$, and the air flow rate, $Q_{\mathrm{g}}$, was changed from 0 to $240 \mathrm{~cm}^{3} / \mathrm{s}$ at equal intervals of $60 \mathrm{~cm}^{3} / \mathrm{s}$. 
Table 1 Mixing time values for different sensor positions.

(a)

\begin{tabular}{|c|c|c|c|c|c|c|c|c|c|}
\hline \multirow[t]{2}{*}{$\begin{array}{c}H_{\mathrm{s}} \\
(\mathrm{cm})\end{array}$} & $\begin{array}{l}Q_{\mathrm{w}} \\
Q_{\mathrm{g}} \\
\end{array}$ & \multicolumn{2}{|r|}{$\begin{array}{c}50 \mathrm{~cm}^{3} / \mathrm{s} \\
0 \mathrm{~cm}^{3} / \mathrm{s}\end{array}$} & $\begin{array}{l}Q_{\mathrm{w}} \\
Q_{\mathrm{g}}\end{array}$ & \multicolumn{2}{|r|}{$\begin{array}{r}100 \mathrm{~cm}^{3} / \mathrm{s} \\
0 \mathrm{~cm}^{3} / \mathrm{s}\end{array}$} & $\begin{array}{c}Q_{\mathrm{w}} \\
Q_{\mathrm{g}}\end{array}$ & \multicolumn{2}{|c|}{$\begin{array}{r}150 \mathrm{~cm}^{3} / \mathrm{s} \\
0 \mathrm{~cm}^{3} / \mathrm{s}\end{array}$} \\
\hline & mean & $\max$ & $\min$ & mean & $\max$ & $\min$ & mean & $\max$ & $\min$ \\
\hline 1 & 52.1 & 58.0 & 47.4 & 22.7 & 28.7 & 17.8 & 15.1 & 16.8 & 13.8 \\
\hline 5 & 49.1 & 53.4 & 47.2 & 22.9 & 25.0 & 19.0 & 15.2 & 17.7 & 12.6 \\
\hline 10 & 46.1 & 51.5 & 41.9 & 21.4 & 27.9 & 14.6 & 14.6 & 17.2 & 11.7 \\
\hline 20 & 50.6 & 57.6 & 41.6 & 26.4 & 29.4 & 21.2 & 14.9 & 17.2 & 12.0 \\
\hline 25 & 51.9 & 60.0 & 44.8 & 26.3 & 29.0 & 21.6 & 14.4 & 16.8 & 12.0 \\
\hline
\end{tabular}

(b)

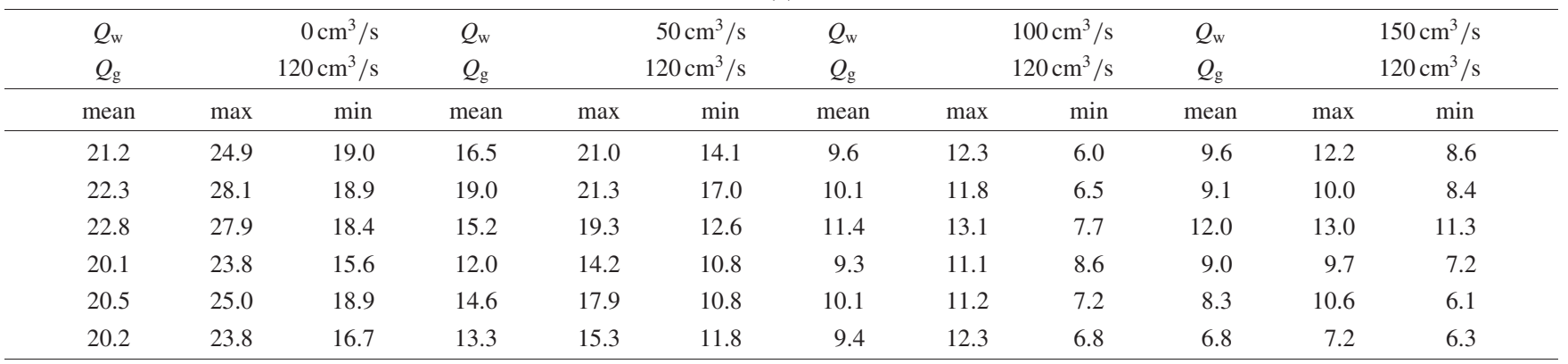

\subsection{Effect of bath depth, $H_{\mathrm{L}}$, on mixing time}

According to previous investigations, ${ }^{13-15)}$ a bottom blown bubbling jet rotates around the vessel axis when the ratio of the bath depth, $H_{\mathrm{L}}$, to the bath diameter, $D$, satisfies a certain condition. This is called the swirl motion of the bubbling jet. Two kinds of swirl motions are known. One is observed for $0.3<H_{\mathrm{L}} / D<1$ and closely related to so-called rotary sloshing ${ }^{16)}$ appearing in a cylindrical bath subjected to external forced oscillation. The swirl radius, $r_{\mathrm{c}}$, of the bubbling jet on the bath surface is relatively small and expressed by $r_{\mathrm{c}}=0.37 R$, where $R$ is the vessel radius. $\left.{ }^{8}{ }^{89}\right)$ The other is induced by a hydrodynamic instability of a large scale ring vortex enclosing the bubbling jet in a bath with $H_{\mathrm{L}} / D>2$. This instability is closely associated with the Coanda effect ${ }^{17)}$ acting on a confined jet near a wall. The bubbling jet approaches the side wall of the vessel and ascends along it while swirling. These two kinds of swirl motions are called, for convenience, the first and second kinds of swirl motions, respectively. ${ }^{13,14)}$

In this study the bath depth, $H_{\mathrm{L}}$, was changed from $5 \mathrm{~cm}$ to $30 \mathrm{~cm}$. The first kind of swirl motion appeared for $H_{\mathrm{L}}=10 \mathrm{~cm}$ and $15 \mathrm{~cm}$, but the second kind did not occur under the present experimental conditions. The sensor and tracer positions are the same as described in Section 2.4.

\subsection{Effect of water injection height, $H_{\mathrm{ni}}$, on mixing time}

Measurements were made for $Q_{\mathrm{w}}=100 \mathrm{~cm}^{3} / \mathrm{s}$, $Q_{\mathrm{g}}=120 \mathrm{~cm}^{3} / \mathrm{s}, H_{\mathrm{L}}=30 \mathrm{~cm}$, and three water injection heights of $H_{\mathrm{ni}}=10,20$, and $30 \mathrm{~cm}$. The same sensor and tracer positions as described in Section 2.4 were chosen here.

\section{Experimental Results and Discussion}

For the sake of simplicity, we denote mixing time values for water injection alone, air injection alone, and simultaneous air and water injection by $T_{\mathrm{m} 1}, T_{\mathrm{m} 2}$, and $T_{\mathrm{m} 3}$, respectively.

3.1 Effects of sensor and tracer positions on mixing time

The measured values of the mixing time for different vertical sensor positions are listed in Table 1 . They are also plotted in Figs. 5 through 7 for individual water flow rate. The scatter of data points at each measurement position was indicated by an error bar. A dashed line for each experimental run denotes a mean value averaged in the axial, i.e., vertical direction. The measured $T_{\mathrm{m} 3}$ values were scattered around the

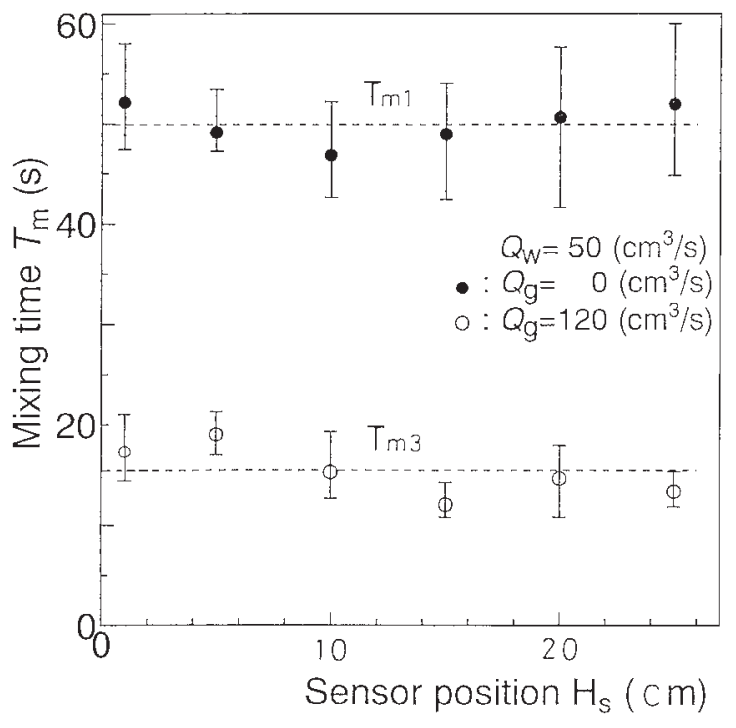

Fig. 5 Relation between mixing time and sensor position for $Q_{\mathrm{w}}=50 \mathrm{~cm}^{3} / \mathrm{s}$. 


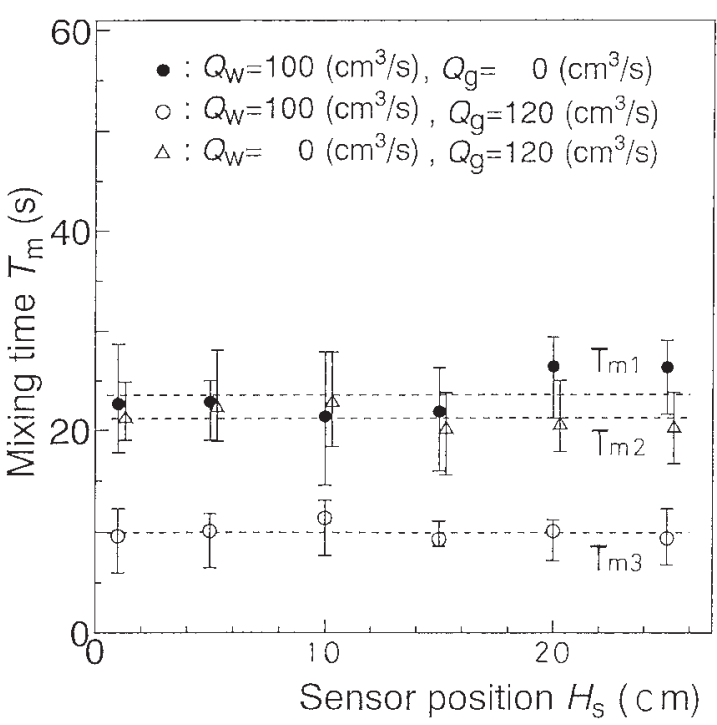

Fig. 6 Relation between mixing time and sensor position for $Q_{\mathrm{w}}=$ $100 \mathrm{~cm}^{3} / \mathrm{s}$.

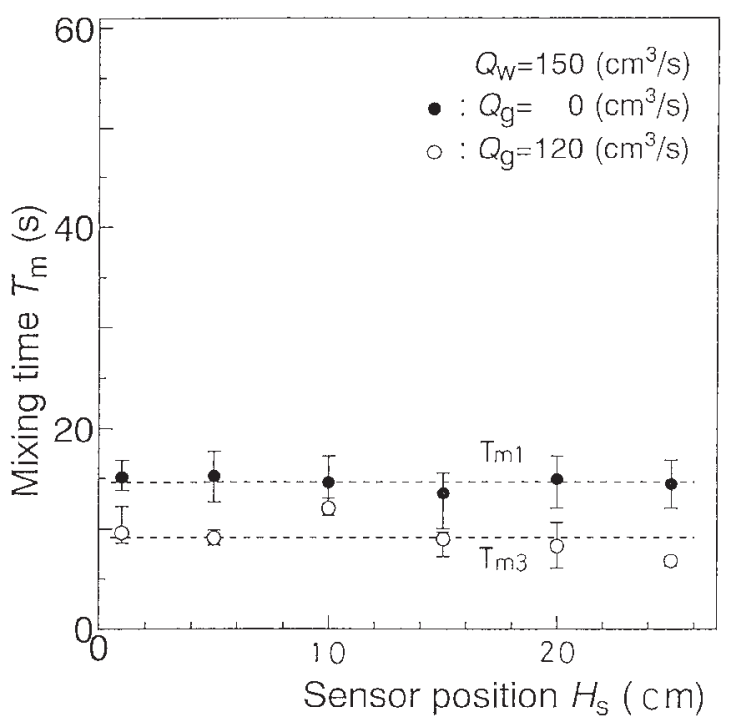

Fig. 7 Relation between mixing time and sensor position for $Q_{\mathrm{w}}=$ $150 \mathrm{~cm}^{3} / \mathrm{s}$.

dashed line within a deviation of $\pm 25 \%$, being much smaller than the scatter of data points at each measurement position. Accordingly it can be said that there exists no definite dependence of $T_{\mathrm{m} 3}$ on $H_{\mathrm{s}}$ under the present experimental conditions.

Figure 8 shows the measured values of the mixing time for different radial sensor and tracer positions. The mixing time was independent of the radial sensor position as well as the tracer position.

\subsection{Effect of water flow rate on mixing time}

Measured values of the mixing time for different water flow rates are shown in Fig. 9 and Table 2. The following relation was found among $T_{\mathrm{m} 1}, T_{\mathrm{m} 2}$ and $T_{\mathrm{m} 3}$.

$$
1 / T_{\mathrm{m} 3}=1 / T_{\mathrm{m} 2}+1 / T_{\mathrm{m} 2}
$$

The dashed line in Fig. 9 denotes the value calculated from

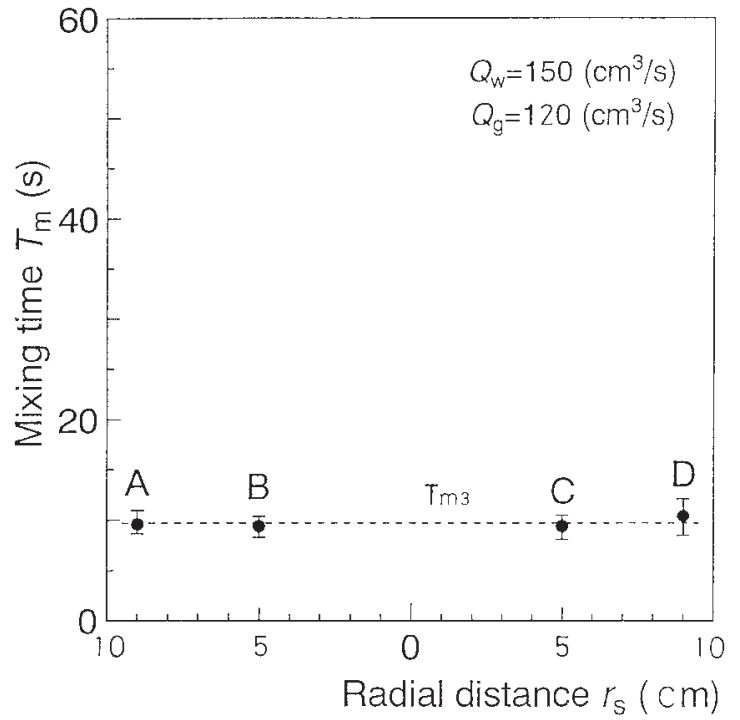

Fig. 8 Mixing time as a function of sensor and tracer positions for $Q_{\mathrm{w}}=$ $150 \mathrm{~cm}^{3} / \mathrm{s}$ and $Q_{\mathrm{g}}=120 \mathrm{~cm}^{3} / \mathrm{s}$.

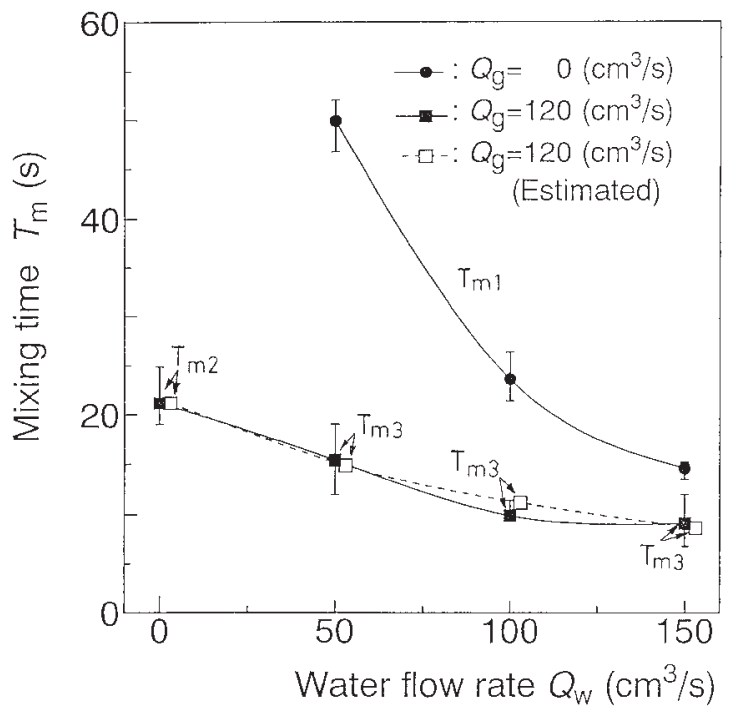

Fig. 9 Relation between mixing time and water flow rate for $Q_{\mathrm{g}}=0$ and $120 \mathrm{~cm}^{3} / \mathrm{s}$.

eq. (1). A good agreement between the measured and calculated values can be seen. Equation (1) has the same functional relationship as that for the combined electrical resistance in the case that two electrical resistances are connected in parallel. The mixing time is regarded as a measure for the flow resistance. A long mixing time value is realized when the flow resistance is high. Therefore, eq. (1) means that the mixing by gas injection proceeds in parallel with the mixing by liquid injection. Taking pictures of the flow field in the bath was difficult because many nozzles were attached to the side wall of the vessel. According to eye inspection of the flow field, however, the flow pattern produced by bottom gas injection in the bath seems to be hardly affected by water injection from the side wall of the vessel when eq. (1) is valid.

Measured mixing time values for water injection alone decreased in inversely proportion to the water flow rate $Q_{\mathrm{w}}$, 
Table 2 Mixing time values for different water flow rates.

\begin{tabular}{|c|c|c|c|c|c|c|c|}
\hline \multirow{2}{*}{$\begin{array}{c}Q_{\mathrm{w}} \\
\left(\mathrm{cm}^{3} / \mathrm{s}\right)\end{array}$} & \multicolumn{2}{|l|}{$Q_{\mathrm{g}}$} & $\mathrm{cm}^{3} / \mathrm{s}$ & \multirow{2}{*}{$\frac{Q_{\mathrm{g}}}{\text { mean }}$} & \multicolumn{2}{|c|}{$120 \mathrm{~cm}^{3} / \mathrm{s}$} & \multirow{2}{*}{$\begin{array}{l}\text { Esti- } \\
\text { mated }\end{array}$} \\
\hline & mean & $\max$ & $\min$ & & $\max$ & $\min$ & \\
\hline 0 & - & - & - & 21.2 & 24.9 & 19.0 & - \\
\hline 100 & 23.6 & 26.4 & 21.4 & 9.9 & 11.4 & 9.3 & 11.2 \\
\hline 150 & 14.6 & 15.2 & 13.5 & 9.1 & 12.0 & 6.8 & 8.7 \\
\hline
\end{tabular}

(unit: s)

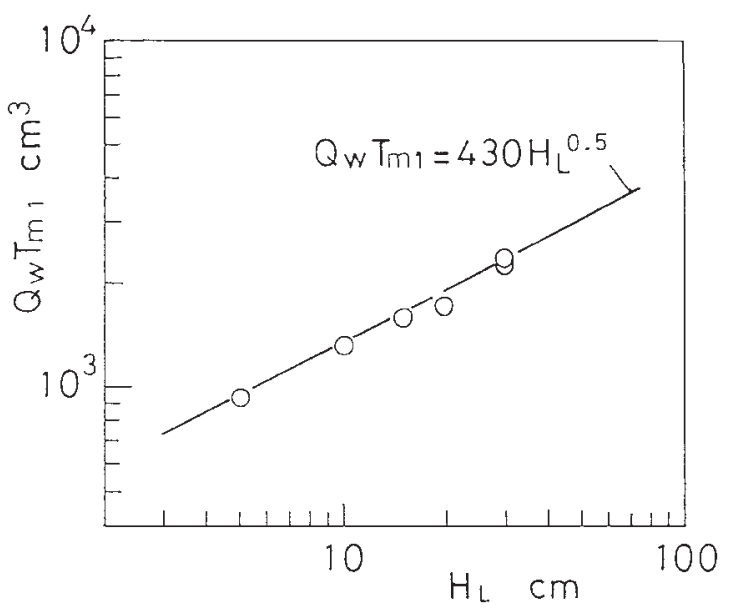

Fig. 10 Comparison of the measured values of mixing time with eq. (2).

as shown in Fig. 10. We derived the following empirical equation considering the dependence of the bath depth, $H_{\mathrm{L}}$, on $T_{\mathrm{m} 1}$ as well.

$$
\begin{aligned}
T_{\mathrm{m} 1}= & 430 H_{\mathrm{L}}{ }^{0.5} Q_{\mathrm{w}}{ }^{-1} \\
& \left(5 \mathrm{~cm} \leqq H_{\mathrm{L}} \leqq 30 \mathrm{~cm},\right. \\
& \left.50 \mathrm{~cm}^{3} / \mathrm{s} \leqq Q_{\mathrm{w}} \leqq 150 \mathrm{~cm}^{3} / \mathrm{s}\right)
\end{aligned}
$$

The adequacy of the relation between $H_{\mathrm{L}}$ and $T_{\mathrm{m} 1}$ will be demonstrated in a later section.

Torii and Yang ${ }^{18)}$ carried out model experiments on the mixing characteristics of gas-powder stirred ladle systems with through flow to determine optimum conditions for solidliquid mixing. Gas was injected together with solid particles into a vessel with a rectangular cross section from a nozzle attached to one of four side walls of the vessel at a constant flow rate. Water was injected and subsequently ejected in a similar manner as described in this study but it was not circulated. The mixing time was defined as a period required for achievement of a uniform particle concentration in the bath. They determined the mixing time using an image processing technique and concluded that the contribution of liquid flow to the mixing time is very small. This result is appreciably different from the present experimental results. Such a difference might be caused by the difference between the experimental facilities used by Torii and Yang ${ }^{18)}$ and the present authors.

\subsection{Effect of gas flow rate on mixing time}

The relationship between the mixing time and air flow rate $Q_{\mathrm{g}}$ is shown in Fig. 11 and Table 3. The measured $T_{\mathrm{m} 3}$ values decreased with an increase in $Q_{\mathrm{g}}$. The dependence of $T_{\mathrm{m} 3}$ on $Q_{\mathrm{g}}$ is relatively weak compared with its dependence on the water flow rate $Q_{\mathrm{w}}$. Equation (1) can approximate the measured $T_{\mathrm{m} 3}$ values satisfactorily.

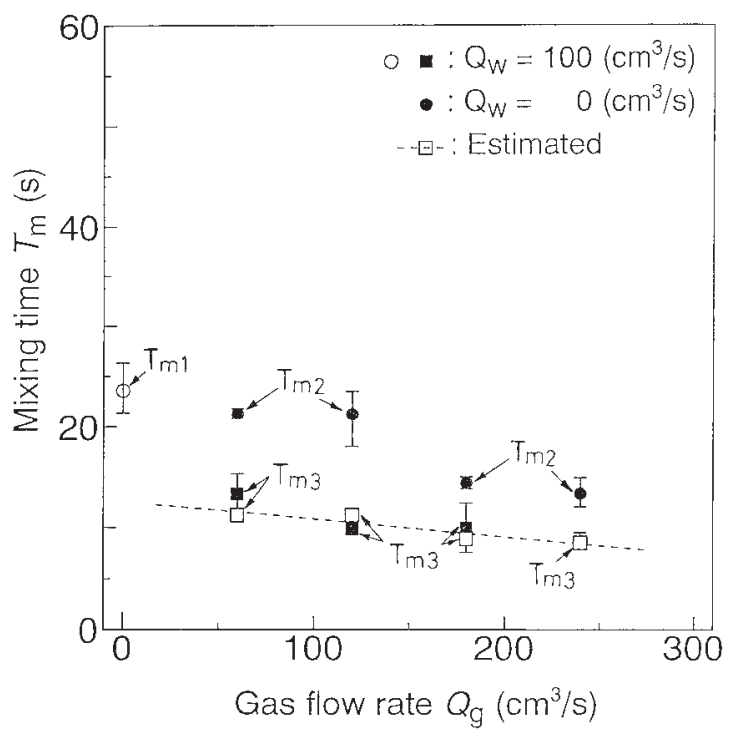

Fig. 11 Relation between mixing time and air flow rate for $Q_{\mathrm{w}}=0$ and

\begin{tabular}{|c|c|c|c|c|c|c|c|}
\hline \multirow{2}{*}{$\begin{array}{l}Q_{\mathrm{g}} \\
\left(\mathrm{cm}^{3} / \mathrm{s}\right)\end{array}$} & \multirow{2}{*}{$\frac{Q_{\mathrm{w}}}{\text { mean }}$} & \multicolumn{2}{|c|}{$0 \mathrm{~cm}^{3} / \mathrm{s}$} & \multirow{2}{*}{$\frac{Q_{\mathrm{w}}}{\text { mean }}$} & \multicolumn{2}{|c|}{$100 \mathrm{~cm}^{3} / \mathrm{s}$} & \multirow{2}{*}{$\begin{array}{l}\text { Esti- } \\
\text { mated }\end{array}$} \\
\hline & & $\max$ & $\operatorname{mix}$ & & $\max$ & $\operatorname{mix}$ & \\
\hline 0 & - & - & - & 23.6 & 26.4 & 21.4 & - \\
\hline 60 & 21.3 & 21.8 & 20.8 & 13.3 & 15.3 & 10.9 & 11.2 \\
\hline 120 & 21.2 & 23.5 & 18.0 & 10.0 & 11.4 & 9.3 & 11.2 \\
\hline 180 & 14.4 & 15.0 & 13.8 & 9.9 & 12.4 & 7.6 & 8.9 \\
\hline 240 & 13.3 & 14.9 & 12.0 & 8.6 & 9.5 & 7.9 & 8.5 \\
\hline
\end{tabular}
$100 \mathrm{~cm}^{3} / \mathrm{s}$.

Table 3 Mixing time values for different air flow rates. 


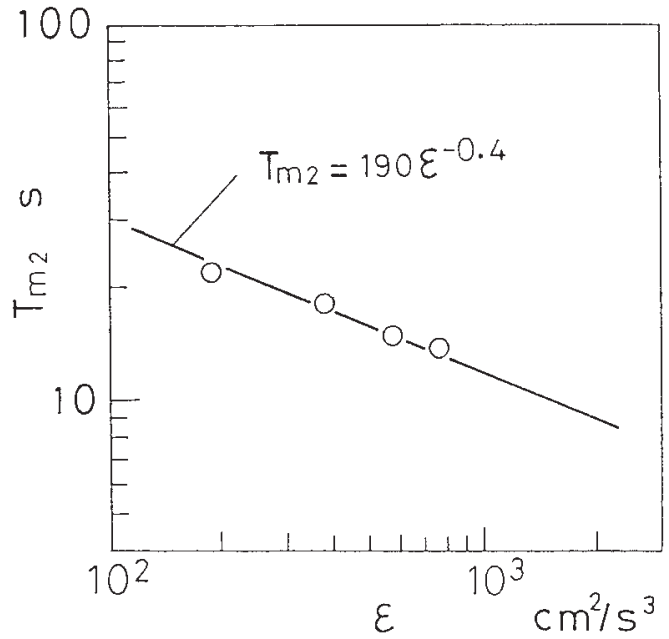

Fig. 12 Comparison of the measured values of mixing time with eq. (4).

Previous investigators ${ }^{1-5)}$ found that the mixing time, $T_{\mathrm{m} 2}$, in a bath stirred by bottom gas injection alone can be correlated as a function of the specific mixing power, $\varepsilon$, defined by

$$
\varepsilon=\rho_{\mathrm{L}} g Q_{\mathrm{g}} H_{\mathrm{L}} /\left(\pi \rho_{\mathrm{L}} H_{\mathrm{L}} D^{2} / 4\right)=4 g Q_{\mathrm{g}} /\left(\pi D^{2}\right)
$$

Nakanishi et al. ${ }^{1)}$ investigated systematically the mixing time in a bath stirred by bottom gas injection and reported that $T_{\mathrm{m} 2}$ is proportional to -0.4 powers of $\varepsilon$. Nowadays it is generally accepted that the power of $\varepsilon$ is dependent on the mode of energy input and the vessel geometry. $5,12,19-22)$

The same functional relationship as derived by Nakanishi et al. ${ }^{1)}$ was valid for the presently measured values, as shown in Fig. 12. The solid line denotes an empirical correlation of $T_{\mathrm{m} 2}$ expressed by

$$
\begin{aligned}
T_{\mathrm{m} 2}= & 190 \varepsilon^{-0.4} \\
& \left(10 \mathrm{~cm} \leqq H_{\mathrm{L}} \leqq 30 \mathrm{~cm},\right. \\
& \left.10^{2} \mathrm{~cm}^{2} / \mathrm{s}^{3}<\varepsilon<10^{3} \mathrm{~cm}^{2} / \mathrm{s}^{3}\right)
\end{aligned}
$$

Nakanishi et al. ${ }^{1)}$ gave a coefficient of 240.

Torii and Yang $^{18)}$ derived two empirical correlations having different dependence on $\varepsilon$, just like Asai et al. ${ }^{21,22)}$

\subsection{Effect of bath depth on mixing time}

Measured values of the mixing time for different bath depths are shown in Fig. 13 and Table 4. In the case of water injection alone, $T_{\mathrm{m} 1}$ increased in proportion to $H_{\mathrm{L}}{ }^{0.5}$. On the

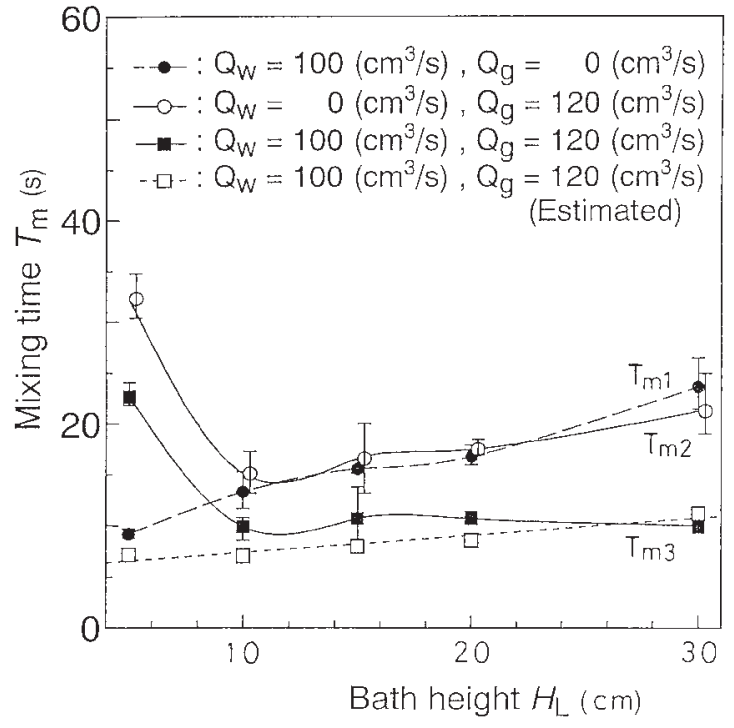

Fig. 13 Relation between mixing time and bath height.

other hand, for gas injection alone, $T_{\mathrm{m} 2}$ remained almost unchanged for $H_{\mathrm{L}} \geqq 10 \mathrm{~cm}$ but increased significantly as $H_{\mathrm{L}}$ became smaller than $10 \mathrm{~cm}$. This is because injected gas leaves out of the bath without transferring most of its energy to water when the bath is shallow. Such a phenomenon is referred here to as "blow out". The mixing time, $T_{\mathrm{m} 3}$, also increased as $H_{\mathrm{L}}$ became smaller than $10 \mathrm{~cm}$. According to a previous study, ${ }^{23,24)}$ a bath contained in a cylindrical vessel can be classified into two types: shallow and deep baths. A motion of a shallow bath is influenced by the bottom wall of the vessel in addition to the side wall of the vessel. On the other hand, a motion of a deep bath is influenced only by the side wall. Therefore, a liquid in a deep bath is much more easier to move than that in a shallow bath. In other words, agitation of a shallow bath is not easy compared to a deep bath. The aspect ratio, $H_{\mathrm{L}} / D$, for the boundary between the two types of baths is 0.3 . This critical aspect ratio is $6 \mathrm{~cm}$ in the present experiment as the vessel diameter, $D$, is $20 \mathrm{~cm}$. This may be another reason why the mixing time increases for $H_{\mathrm{L}}<10 \mathrm{~cm}$.

The first kind of swirl motion took place for $H_{\mathrm{L}}=10 \mathrm{~cm}$ and $15 \mathrm{~cm}$ when the bath was agitated by gas injection alone. The same kind of swirl motion occurred in the bath accompanied by simultaneous gas and water injection but it

\begin{tabular}{|c|c|c|c|c|c|c|c|c|c|c|}
\hline \multirow[t]{2}{*}{$\begin{array}{c}H_{\mathrm{L}} \\
(\mathrm{cm})\end{array}$} & $\begin{array}{c}Q_{\mathrm{w}} \\
Q_{\mathrm{g}} \\
\end{array}$ & \multicolumn{2}{|r|}{$\begin{array}{r}100 \mathrm{~cm}^{3} / \mathrm{s} \\
0 \mathrm{~cm}^{3} / \mathrm{s}\end{array}$} & $\begin{array}{l}Q_{\mathrm{w}} \\
Q_{\mathrm{g}} \\
\end{array}$ & \multicolumn{2}{|c|}{$\begin{array}{r}0 \mathrm{~cm}^{3} / \mathrm{s} \\
120 \mathrm{~cm}^{3} / \mathrm{s} \\
\end{array}$} & $\begin{array}{l}Q_{\mathrm{w}} \\
Q_{\mathrm{g}}\end{array}$ & \multicolumn{2}{|c|}{$\begin{array}{l}100 \mathrm{~cm}^{3} / \mathrm{s} \\
120 \mathrm{~cm}^{3} / \mathrm{s}\end{array}$} & \multirow[t]{2}{*}{$\begin{array}{l}\text { Esti- } \\
\text { mated }\end{array}$} \\
\hline & mean & $\max$ & $\min$ & mean & $\max$ & $\min$ & mean & $\max$ & $\min$ & \\
\hline 5 & 9.2 & 9.7 & 8.8 & 32.3 & 34.8 & 30.4 & 22.7 & 24.1 & 21.9 & 7.2 \\
\hline 10 & 13.3 & 15.3 & 11.7 & 15.1 & 17.3 & 13.2 & 9.9 & 10.8 & 8.6 & 7.1 \\
\hline 15 & 15.6 & 16.4 & 15.2 & 16.6 & 20.0 & 13.2 & 10.7 & 13.8 & 8.7 & 8.0 \\
\hline 20 & 16.8 & 17.9 & 16.0 & 17.5 & 18.5 & 17.0 & 10.7 & 11.4 & 10.3 & 8.6 \\
\hline 30 & 23.6 & 26.4 & 21.4 & 21.2 & 24.9 & 19.0 & 10.0 & 11.4 & 9.3 & 11.2 \\
\hline
\end{tabular}
did not affect the mixing time just like the case of gas injection alone. ${ }^{89}$ Figure 13 indicates that eq. (1) can

Table 4 Mixing time values for different bath depths. 
Table 5 Mixing time values for different water injection heights.

\begin{tabular}{|c|c|c|c|c|c|c|c|c|c|c|}
\hline \multirow[t]{2}{*}{$\begin{array}{l}H_{\mathrm{ni}} \\
(\mathrm{cm})\end{array}$} & $\begin{array}{l}Q_{\mathrm{w}} \\
Q_{\mathrm{g}} \\
\end{array}$ & \multicolumn{2}{|r|}{$\begin{array}{r}100 \mathrm{~cm}^{3} / \mathrm{s} \\
0 \mathrm{~cm}^{3} / \mathrm{s}\end{array}$} & $\begin{array}{c}Q_{\mathrm{w}} \\
Q_{\mathrm{g}}\end{array}$ & \multicolumn{2}{|c|}{$\begin{array}{r}0 \mathrm{~cm}^{3} / \mathrm{s} \\
120 \mathrm{~cm}^{3} / \mathrm{s} \\
\end{array}$} & $\begin{array}{l}Q_{\mathrm{w}} \\
Q_{\mathrm{g}} \\
\end{array}$ & \multicolumn{2}{|c|}{$\begin{array}{l}100 \mathrm{~cm}^{3} / \mathrm{s} \\
120 \mathrm{~cm}^{3} / \mathrm{s}\end{array}$} & \multirow[t]{2}{*}{$\begin{array}{l}\text { Esti- } \\
\text { mated }\end{array}$} \\
\hline & mean & $\max$ & $\min$ & mean & $\max$ & $\min$ & mean & $\max$ & $\min$ & \\
\hline 10 & 26.7 & 27.6 & 26.2 & 21.2 & 24.9 & 19.0 & 10.1 & 10.5 & 9.6 & 11.8 \\
\hline 20 & 25.7 & 28.8 & 21.2 & 21.2 & 24.9 & 19.0 & 12.6 & 14.9 & 10.6 & 11.6 \\
\hline 30 & 23.6 & 26.4 & 21.4 & 21.2 & 24.9 & 19.0 & 10.0 & 11.4 & 9.3 & 11.2 \\
\hline
\end{tabular}

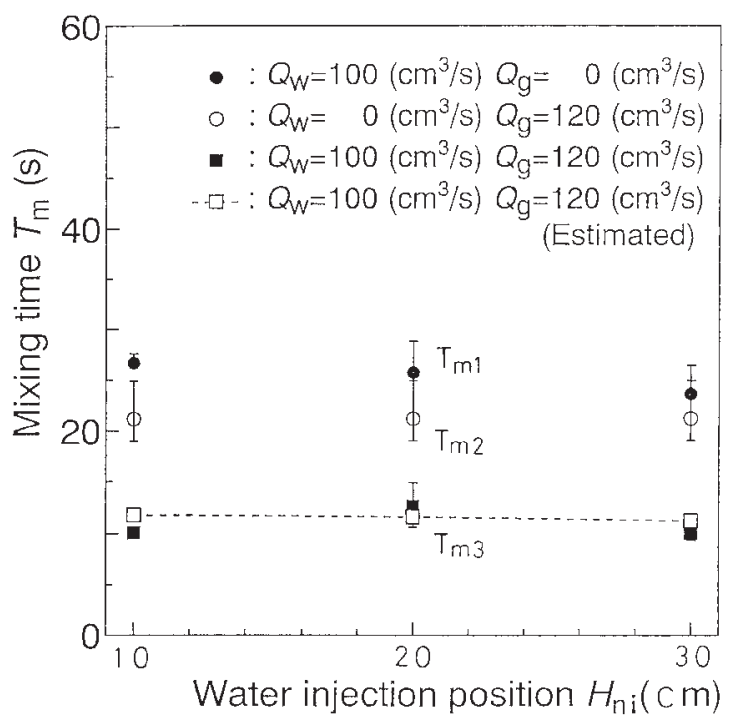

Fig. 14 Relation between mixing time and water injection height.

reasonably approximate the measured $T_{\mathrm{m} 3}$ values in the absence of the blow out phenomenon for $H_{\mathrm{L}}>10 \mathrm{~cm}$.

\subsection{Effect of injection height of water, $H_{n i}$, on mixing time}

Experimental results of the mixing time are shown against the nozzle height, $H_{\text {ni }}$, in Fig. 14 and Table 5. The measured values are in good agreement with eq. (1) for $H_{\mathrm{ni}}$ from $10 \mathrm{~cm}$ to $30 \mathrm{~cm}$.

\subsection{Effects of vessel diameter, $D$, ejection height of water, $H_{n e}$, and other parameters on mixing time}

Effects of influential parameters such as $D$ and $H_{\text {ne }}$ on the mixing time, $T_{\mathrm{m} 3}$, will be investigated in a future study.

\section{Conclusions}

A fundamental investigation was carried out on the mixing time in a cylindrical bath agitated simultaneously by bottom gas injection and side liquid injection. For example, information on the mixing time is useful for developing a new batch type process for wastewater treatment. The results obtained in this study are summarized as follows:

(1) The mixing time in a bath with simultaneous air and water injection, $T_{\mathrm{m} 3}$, is nearly constant in the whole bath irrespective of the sensor and tracer positions.

(2) In the absence of the blow out phenomenon, the mixing time in a bath with simultaneous gas and water injection, $T_{\mathrm{m} 3}$, can be correlated by the following empirical equation.

$$
1 / T_{\mathrm{m} 3}=1 / T_{\mathrm{m} 2}+1 / T_{\mathrm{m} 2}
$$

where $T_{\mathrm{m} 1}$ and $T_{\mathrm{m} 2}$ denote the mixing time values for water injection alone and air injection alone, respectively. This equation has the same functional relationship as that for the combined electrical resistance in the case that two electrical resistances are connected in parallel. Therefore, mixing by gas injection and that by water injection proceed in parallel with each other.

(3) The measured values of $T_{\mathrm{m} 1}$ and $T_{\mathrm{m} 2}$ are approximated by the following empirical equations under the present experimental conditions.

$$
\begin{aligned}
& T_{\mathrm{m} 1}=430 H_{\mathrm{L}}^{0.5} Q_{\mathrm{w}}^{-1} \\
& T_{\mathrm{m} 2}=190 \varepsilon^{-0.4}
\end{aligned}
$$

where $H_{\mathrm{L}}$ is the bath depth, $Q_{\mathrm{w}}$ is the water flow rate, and $\varepsilon$ is the specific mixing power.

\section{Nomenclature}

$D$ : inner diameter of vessel $(\mathrm{cm})$

$d_{\mathrm{n}}$ : inner diameter of bottom nozzle for gas injection $(\mathrm{cm})$

$d_{\mathrm{nw}}$ : inner diameter of side nozzle for water injection $(\mathrm{cm})$

$H_{\mathrm{L}}$ : bath depth $(\mathrm{cm})$

$H_{\mathrm{ne}}$ : nozzle height for water drainage $(\mathrm{cm})$

$H_{\mathrm{ni}}$ : nozzle height for water injection $(\mathrm{cm})$

$H_{\mathrm{s}}$ : height of electric conductivity sensor $(\mathrm{cm})$

$Q_{\mathrm{g}}$ : gas flow rate $\left(\mathrm{cm}^{3} / \mathrm{s}\right)$

$Q_{\mathrm{w}}$ : water flow rate $\left(\mathrm{cm}^{3} / \mathrm{s}\right)$

$r_{\mathrm{s}}:$ radial sensor position $(\mathrm{cm})$

$r_{\mathrm{t}}$ : radial tracer addition position $(\mathrm{cm})$

$T_{\mathrm{m}}$ : mixing time (s)

$T_{\mathrm{m} 1}$ : mixing time for water injection alone (s)

$T_{\mathrm{m} 2}$ : mixing time for air injection alone (s)

$T_{\mathrm{m} 3}$ : mixing time for simultaneous water and gas injection (s)

$\varepsilon$ : specific mixing power $\left(\mathrm{cm}^{2} / \mathrm{s}^{3}\right)$

\section{REFERENCES}

1) K. Nakanishi, T. Fujii and J. Szekely: Ironmak. Steelmak. 2 (1975) 193.

2) G. G. K. Murthy, S. P. Mehrotra and A. Ghosh: Process Technology Proc. 6-3 (1986) 401.

3) G. G. K. Murthy and J. F. Elliot: ISIJ Int. 32 (1992) 190.

4) U. P. Sinha and M. J. McNallan: Metall. Trans. 16B (1985) 850.

5) D. Mazumdar and R. I. L. Guthrie: Matall. Trans. 17B (1986) 725

6) J. Mietz and F. Oeters: Steel Research 58 (1987) 446.

7) M. Zhu, T. Inomoto, M. Yano and I. Sawada: CAMP-ISIJ 7 (1994) 263.

8) M. Iguchi, S. Hosohara, T. Kondoh, Y. Ito and Z. Morita: Tetsu-to- 
Hagane 79 (1993) 934.

9) M. Iguchi, S. Hosohara, T. Kondoh, Y. Ito and Z. Morita: ISIJ Int. 34 (1994) 330.

10) M. Iguchi, Y. Sasaki, K. Sasaki and J. Yoshida: J. Jpn. Soc. Multiphase Flow, 16-3 (2002-9) 232

11) M. Shitara, M. Iguchi, K. Takano, T. Tamamori, H. Shitara and T. Maruyama: Mater. Trans. 44 (2003) 2456.

12) D. Mazumdar and R. I. L. Guthrie: ISIJ Int. 35 (1995) 1.

13) M. Iguchi, S. Hosohara, T. Koga, R. Yamaguchi and Z. Morita: Tetsuto-Hagane 78 (1992) 1778; ISIJ Int. 33 (1993) 1037.

14) M. Iguchi, S. Hosohara, T. Koga, R. Yamaguchi and Z. Morita: ISIJ Int. 33 (1993) 1037.

15) Y. Kato, K. Nakanishi, T. Nozaki, K. Suzuki and T. Emi:Tetsu-toHagane 68 (1982) 1604.

16) Jpn. Soc. Fluid dynamics: Handbook for Fluid Dynamics, (Maruzen,
1987) p. 720.

17) Jpn Hydraulics and Pneumatics Soc., Handbook for Hydraulics and Pneumatics, (Ohm Pub.Co. 1989) p. 51.

18) S. Torii and W. J. Yang: Proc. 30th Jpn National Symp. Heat Transfer, (1993) p. 121.

19) M. Sano and K. Mori: Tetsu-to-Hagane 68 (1982) p. 2451.

20) M. Sano and K. Mori: Trans. ISIJ 22 (1983) 169.

21) S. Asai, T. Okamoto, J. C. He and I. Muchi: Tetsu-to-Hagane 68 (1982) 426; Trans. ISIJ 25 (1985) 43.

22) S. Asai, T. Okamoto, J. C. He and I. Muchi: Trans. ISIJ 25 (1985) 43.

23) A. Kimura and H. Ohashi: Trans. Jpn. Sco. Mech. Eng., Pt. 144 (1978) 3024 .

24) A. Kimura and H. Ohashi: Trans. Jpn. Soc. Mech. Eng., Pt. 144 (1978) 3446 . 